\title{
Chemical composition and nutritional value of the main cultivated mushrooms in Zhejiang province, China: An inter-species comparative study \\ Qiaomei $\mathrm{Ru}^{1, \mathrm{a}}$, Jinzhe $\mathrm{He}^{2, \mathrm{~b}}$ \\ ${ }^{1}$ Department of Biotechnology, Hangzhou Wanxiang Polytechnic, Hangzhou, Zhejiang 310023; \\ ${ }^{2}$ School of Ocean College, Zhejiang University of Technology, Hangzhou 310032. \\ a1483091098@qq.com, b183002890@qq.com
}

Keywords: cultivated mushrooms, nutritional value, amino acid, heavy metal

\begin{abstract}
Herein, it was reported and compared the chemical composition and nutritional value of the main cultivated mushroom in Zhejiang province, China: Agaricus bisporus, Auricularia auricula, Flammulina velutipes and Lentinus edodes. A. bisporus revealed the highest levels of protein and fat, while A. auricula contained the lowest fiber and fat. The amount of the essential amino acids in $A$. bisporus was highest among the mushrooms used in this study. L. edodes had the highest concentrations of $\mathrm{S}$ and the other three species had the highest $\mathrm{P}$ contents. The four main cultivated mushrooms were also rich in $\mathrm{K}$, the lowest contents of $\mathrm{Mg}$, $\mathrm{Ca}$ and $\mathrm{Na}$ were measured in L. edodes. A 4-fold difference in $\mathrm{Zn}$ concentration was found L. edodes and A. auricular. The highest Cu level was $23.93 \mathrm{mg} / \mathrm{g}$ for the A. bisporus, and the lowest Cu level was $2.40 \mathrm{mg} / \mathrm{g}$ for A. auricular. The levels of As in A. bisporus, Cd in L. edodes and $\mathrm{Cr}$ in these four main cultivated mushrooms exceeded the national standard. This study contributes to the elaboration of nutritional databases of the most consumed fungi species worldwide, allowing comparison between them.
\end{abstract}

\section{Introduction}

Mushrooms might be used directly in diet and promote health since they have a great nutritional value. More than 3000 mushrooms are said to be "the main edible species", of which only 100 are commercially cultivated, and only 10 of those on an industrial scale [1]. Production of mushrooms continuously increases over time, being China the biggest producer. The most cultivated mushrooms are A. bisporus, A. auricula, F. velutipes and L. edodes. These species require shorter growth time when compared to other edible mushrooms, they demand few environmental controls, and they can be cultivated in a simple and cheap way. Herein, it was intended to provide information about the nutritional value and chemical composition of the main cultivated mushrooms in Zhejiang province.

\section{Material and methods}

\subsection{Mushroom species.}

Fresh fruiting bodies of A. bisporus, A. auricular, F. velutipes and L. edodes were collected from Zhejiang Agriculture Research Institute, Longquan City, Jiangshan City and Qingyuan County in Zhejiang Province, China, respectively. All of the mushrooms were dried at $65^{\circ} \mathrm{C}$ for $24 \mathrm{~h}$ and grind for further analysis.

\subsection{Standards and reagents.}

All other chemicals and solvents were of analytical grade and purchased from common sources. Water was treated in a Milli-Q water purification system (TGI Pure Water Systems, USA).

\subsection{Nutritional value.}

The samples were analysed for chemical composition (ash, proteins, fiber, fat, and carbohydrates) using the AOAC procedures (AOAC, 1995). The ash content was determined by incineration at $600 \pm$ $15^{\circ} \mathrm{C}$, the crude protein content $(\mathrm{N} \times 4.38)$ of the samples was estimated by the macro-Kjeldahl 
method; the crude fat was determined by extracting a known weight of powdered sample with petroleum ether, using a Soxhlet apparatus. Total carbohydrates were calculated by difference.

\subsection{Free amino acid assay.}

Air-dried mushroom powder (500 mg) was shaken with $50 \mathrm{ml}$ of $0.1 \mathrm{~N} \mathrm{HCl}$ (Union Chemical Co., Hsinchu, Taiwan) for 45 min at ambient temperature and filtered through Whatman No. 4 filter paper. The filtrate was then passed through a filter unit (13 mm, Lida), and filtered using a $0.45-\mathrm{mm}$ CA non-sterile filter (Lida). The purified filtrate was mixed with $o$-phthal-aldehyde reagent (Sigma) in an Eppendorf tube, shaken to facilitate derivatisation and then immediately injected onto the HPLC.

The HPLC system was the same as for sugar analysis but included a Hitachi F-1050 fluorescence detector with fluorescence excitation at $340 \mathrm{~nm}$ and emission at $450 \mathrm{~nm}$, and a Prodigy 5 ODS-2 column $(4.6 \times 250 \mathrm{~mm}, 5 \mu$, Phenomenex Inc., Torrance, CA). The mobile phases and gradient conditions were the same as described in Mau et al. (1997). Each amino acid was quantified by the calibration curve of the authentic amino acid.

\subsection{Mental analysis.}

Collected wheat grain samples were dried at $70^{\circ} \mathrm{C}$ in a drying cabinet with air circulation until they reached constant weight. Later, about $0.5 \mathrm{~g}$ dried and ground sample was digested by using $5 \mathrm{ml}$ of $65 \% \mathrm{HNO}_{3}$ and $2 \mathrm{ml}$ of $35 \% \mathrm{H}_{2} \mathrm{O}_{2}$ in a closed microwave system (Cem-MARS Xpress). The volumes of the digested samples were completed to $20 \mathrm{ml}$ with ultra-deionized water and mineral concentrations were determined by inductively coupled plasma-optical emission spectroscopy (Vista-Pro Axial; Varian Pty Ltd, Australia).

Appropriate quality assurance procedures and precautions were carried out to ensure the reliability of the results. The standard reference material, chicken powder (GBW10018), was obtained from the National Standard Substance Research Center (NSSRC), China and digested with the samples to validate the analytical procedures. The standard solutions used for the calibration procedures were prepared by diluting the stock solution with $1 \%(\mathrm{v} / \mathrm{v}) \mathrm{HNO}_{3}$.

\subsection{Statistical analysis.}

All results were expressed as means \pm standard deviation (SD) of three replications, and the one-way analysis of variance (ANOVA) was used for the statistical analysis.

\section{Results and discussion}

The results of the nutritional value obtained for the main cultivated mushrooms in Zhejiang province are shown in Table 1 . Ash ranges between $4.00 \%$ in A. auricula and $7.00 \%$ in A. bisporus. A. bisporus gave the highest level of protein(29.38\%). Mushrooms are reported to be a good source of protein, and some investigators have even contended that the amino acid compositions of mushrooms are comparable to animal proteins [2]. F. velutipes revealed the highest fiber (14.83\%) contents; $A$. auricula gave the lowest fat levels (0.67\%). In general, mushrooms are low-calorie foods since they provide low amounts of fat [1]. Carbohydrates, calculated discounting protein, ash and fat levels, were the most abundant macronutrients and the highest levels were also found in L. edodes (43.20\%). Although, an extraordinarily high level of total fiber was reported for A. bisporus, and L. edodes gave the highest carbohydrates levels. Carbohydrates content includes also fiber such as the structural polysaccharides $\beta$-glucans, chitin, hemicelluloses and pectic substances [3]. F. velutipes studied here presented similar ash and fiber level, but lower carbohydrate, fat and protein, while L. Edodes herein studied was discribed lower ash, carbohydate and fat, but higher fiber and protein compared to the samples from Taiwan [4]. It is known that the growth compost can influence the chemical composition and, as a comsequence, the nutritional value of the cultivated mushrooms. Mushroom quality is also influenced by other qarameters such as the stage of development and pre and post-harvest conditions. All these interfering factors justify the variability in compositon data published by didderent authers working with even the same species of mushroom [5]. 
Table 1 Proximate composition of four main cultivated mushrooms in Zhejiang province

\begin{tabular}{lllll}
\hline Component & L. edodes & A. bisporus & F. velutipes & A. auricula \\
\hline Ash & $4.83 \pm 0.225$ & $7.00 \pm 0.264$ & $6.67 \pm 0.153$ & $4.00 \pm 0.100$ \\
Protein & $23.48 \pm 0.025$ & $29.38 \pm 0.234$ & $15.59 \pm 0.345$ & $13.14 \pm 0.056$ \\
Fiber & $7.50 \pm 0.108$ & $7.30 \pm 0.046$ & $14.83 \pm 0.103$ & $5.40 \pm 0.121$ \\
Fat & $2.07 \pm 0.042$ & $3.87 \pm 0.031$ & $2.12 \pm 0.024$ & $0.67 \pm 0.006$ \\
Carbohydrates & $43.20 \pm 0.305$ & $37.30 \pm 0.296$ & $38.83 \pm 0.454$ & $32.27 \pm 0.202$ \\
\hline
\end{tabular}

Generally, leucine, valine, glutamine, glutamic and aspartic acids are the most abundant amino acids in mushrooms, which were analysed by different techniques such as ionic exchange chromatography coupled to an amino acids analyzer, reaction with ninhydrin using an amino acids analyzer, gas chromatography coupled to mass spectrometry (GC-MS), high performance chromatography (HPLC) with UV-Vis detection and HPLC-fluorescence [6]. The composition and amount of amino acids varied with mushroom species (Table 2). Comparing the total amounts of the essential amino acids in the three mushroom species, the amount of the essential amino acids in $A$. bisporus was highest among the mushrooms used in this study. The fruiting body of $A$. bisporus contained $6.75 \mathrm{~g}$ essential amino acids/100 g of edible weight, while A. auricula had $3.94 \mathrm{~g}$ essential amino acids/100 g of edible weight, respectively. Additionally, methionine was the most abundant components of essential amino acids in F. velutipes. ( $0.94 \mathrm{~g} / 100 \mathrm{~g})$. The most abundant component of essential amino acid was leucine in three mushrooms except $F$. velutipes. A. auricula contained 0.83 $\mathrm{g}$ leucine/100 g of edible weight, while L. edodes and A. bisporus contained $1.29 \mathrm{~g}$ and $1.28 \mathrm{~g}$ leucine/100 g of edible weight, respectively. The major component of non-essential amino acid, glutamate, ranged from $1.51 \mathrm{~g}$ to $1.92 \mathrm{~g} / 100 \mathrm{~g}$ of $A$. auricular and F. velutipes. Moreover, the amount of glutamate was higher in L. edodes (4.35 g/100 g) and A. bisporus (4.86 g/100 g). These results were similar to the reports that leucine and glutamate were the most abundant component of essential and non-essential amino acids in P. Ostreatus [7-8]. Asparagic acid, serine, cysteine, histidine and arginine were more abundant in $L$. edodes than other mushrooms. While, glycine, alanine, prolinewere more abundant in A. bisporus than other mushrooms. Additionally, the essential and non-essential amino acids in the main cultivated mushrooms in Zhejiang province were more abundant than three edible mushroom in Korea [6].

Table 2 Amino acid profile of four main cultivated mushrooms in Zhejiang province

\begin{tabular}{lllll}
\hline Amino acids & L. edodes & A. bisporus & F. velutipes & A. auricula \\
\hline Threonine & $0.93 \pm 0.035$ & $0.90 \pm 0.006$ & $0.57 \pm 0.014$ & $0.68 \pm 0.008$ \\
Valine & $0.88 \pm 0.034$ & $0.99 \pm 0.006$ & $0.61 \pm 0.006$ & $0.57 \pm 0.008$ \\
Methionine & $0.73 \pm 0.008$ & $0.92 \pm 0.009$ & $0.94 \pm 0.035$ & $0.29 \pm 0.005$ \\
Isoleucine & $0.67 \pm 0.028$ & $0.74 \pm 0.003$ & $0.40 \pm 0.004$ & $0.37 \pm 0.002$ \\
Leucine & $1.29 \pm 0.051$ & $1.28 \pm 0.006$ & $0.81 \pm 0.011$ & $0.83 \pm 0.006$ \\
Phenylalanine & $0.78 \pm 0.031$ & $0.80 \pm 0.004$ & $0.62 \pm 0.012$ & $0.48 \pm 0.005$ \\
Lysine & $0.98 \pm 0.039$ & $0.80 \pm 0.003$ & $0.70 \pm 0.019$ & $0.56 \pm 0.002$ \\
Total essential amino acids & 6.26 & 6.43 & 4.65 & 3.78 \\
Aspartate & $1.63 \pm 0.058$ & $1.50 \pm 0.005$ & $1.05 \pm 0.022$ & $1.09 \pm 0.011$ \\
Glutamate & $4.35 \pm 0.161$ & $4.86 \pm 0.054$ & $1.92 \pm 0.065$ & $1.51 \pm 0.017$ \\
Serine & $0.94 \pm 0.033$ & $0.92 \pm 0.003$ & $0.56 \pm 0.014$ & $0.62 \pm 0.006$ \\
Glycine & $0.85 \pm 0.031$ & $0.93 \pm 0.003$ & $0.58 \pm 0.008$ & $0.54 \pm 0.004$ \\
Cysteine & $0.48 \pm 0.013$ & $0.35 \pm 0.002$ & $0.29 \pm 0.003$ & $0.19 \pm 0.009$ \\
Histidine & $0.39 \pm 0.015$ & $0.36 \pm 0.002$ & $0.24 \pm 0.004$ & $0.32 \pm 0.004$ \\
Arginine & $0.91 \pm 0.037$ & $0.90 \pm 0.002$ & $0.56 \pm 0.009$ & $0.63 \pm 0.009$ \\
Alanine & $1.05 \pm 0.040$ & $1.77 \pm 0.028$ & $0.75 \pm 0.007$ & $0.85 \pm 0.010$ \\
Proline & $0.62 \pm 0.032$ & $0.80 \pm 0.023$ & $0.33 \pm 0.005$ & $0.47 \pm 0.004$ \\
Tyrosine & $0.37 \pm 0.007$ & $0.42 \pm 0.003$ & $0.55 \pm 0.017$ & $0.34 \pm 0.004$ \\
Total non-essential amino acids & 11.59 & 12.81 & 6.83 & 6.56 \\
Total amino acids & 17.85 & 19.24 & 11.48 & 10.34 \\
\hline
\end{tabular}


The mean concentrations of macroelement for the main cultivated mushrooms in Zhejiang province are shown in Table 3. Macroelement contents varied among the four species. L. edodes had the highest concentrations of $S$ (10298.71 $\mathrm{g} \mathrm{kg}^{-1}$, respectively) and the other three species (A. bisporus, F. velutipes, A. auricular) had the highest P contents (12359.35, 6203.29, and $2891.24 \mathrm{~g}$ $\mathrm{kg}^{-1}$, respectively). The four main cultivated mushrooms were also rich in $\mathrm{K}$, and the highest $\mathrm{K}$ concentration was mesasured in A. bisporus (6029.62 $\mathrm{g} \mathrm{kg}^{-1}$ ). A comparatively constant level was noted in Mg, which was from $835.42 \mathrm{~g} \mathrm{~kg}^{-1}$ in L. edodes to $1054.18 \mathrm{~g} \mathrm{~kg}^{-1}$ in F. velutipes. The highest content of Ca was found in A. auricular (2354.50 g kg-1), much higher than other three species. It was worth noting that the lowest contents of $\mathrm{Mg}$, $\mathrm{Ca}$ and $\mathrm{Na}$ were measured in L. edodes.

Table 3 Macroelement level of four main cultivated mushrooms in Zhejiang province

\begin{tabular}{lllll}
\hline Macroelement & L. edodes & A. bisporus & F. velutipes & A. auricula \\
\hline $\mathrm{Ca}$ & $168.60 \pm 6.151$ & $272.24 \pm 9.059$ & $233.45 \pm 8.126$ & $2354.50 \pm 114.889$ \\
$\mathrm{~K}$ & $4594.31 \pm 8.932$ & $6029.62 \pm 31.174$ & $4937.14 \pm 43.310$ & $2802.36 \pm 122.702$ \\
$\mathrm{Mg}$ & $835.42 \pm 9.832$ & $854.31 \pm 5.770$ & $1054.18 \pm 15.626$ & $1021.24 \pm 15.150$ \\
$\mathrm{Na}$ & $51.81 \pm 1.090$ & $363.24 \pm 8.190$ & $147.37 \pm 5.961$ & $317.69 \pm 12.736$ \\
$\mathrm{P}$ & $7246.59 \pm 59.133$ & $12359.35 \pm 108.449$ & $6203.29 \pm 153.154$ & $2891.24 \pm 85.896$ \\
$\mathrm{~S}$ & $10298.71 \pm 17.789$ & $1977.30 \pm 15.669$ & $1206.47 \pm 11.079$ & $670.64 \pm 3.554$ \\
\hline
\end{tabular}

The trace elements are of great biochemical interest and they have nutritional and clinical importance. For example, Se and Zn play very important roles in human and animal metabolism, because they are constituents of various enzymes of clinical significance. The mean concentrations of microelements of each individual species were shown in Table 4. Generally, the individual species the concentrations of microelement varied to some extent. There was a 4 -fold difference in $\mathrm{Zn}$ concentration between L. edodes and A. auricular. However, the concentration of Co did not vary in the individual species. Fe concentration ranged from 41.15 in $L$. edodes to $107.72 \mathrm{mg} \mathrm{kg}^{-1}$ in $F$. velutipes. A more than 3-fold difference in Al concentration was found between L. edodes and A. bisporus. The highest $\mathrm{Cu}$ level was $23.93 \mathrm{mg} / \mathrm{g}$ for the $A$. bisporus, and the lowest $\mathrm{Cu}$ level was 2.40 $\mathrm{mg} / \mathrm{g}$ for $A$. auricular. The highest $\mathrm{Mn}$ level was found in A. auricular (21.53 $\mathrm{mg} / \mathrm{g}$ ) and the lowest was found in F. velutipes (5.38 mg/g). The level of Se in A. bisporus (5.55 mg/g) was higher than the other three main cultivated mushrooms. According to previous studies, it appears A. Bisporus from Zhejiang province had lower $\mathrm{Cu}$ and $\mathrm{Co}$, but higher Fe, $\mathrm{Mn}$ and $\mathrm{Zn}$ levels than sample from Turkey [9].

Table 4 Microelement level of four main cultivated mushrooms in Zhejiang province

\begin{tabular}{lllll}
\hline Microelement & L. edodes & A. bisporus & F. velutipes & A. auricula \\
\hline $\mathrm{Al}$ & $20.66 \pm 1.045$ & $63.03 \pm 2.219$ & $43.43 \pm 0.993$ & $56.19 \pm 3.860$ \\
$\mathrm{Co}$ & $0.02 \pm 0.001$ & $0.02 \pm 0.001$ & $0.02 \pm 0.002$ & $0.02 \pm 0 . .02$ \\
$\mathrm{Cu}$ & $10.73 \pm 0.219$ & $23.93 \pm 0.776$ & $4.49 \pm 0.077$ & $2.40 \pm 0 . .59$ \\
$\mathrm{Fe}$ & $41.15 \pm 0.995$ & $93.37 \pm 2.692$ & $107.72 \pm 0.605$ & $71.27 \pm 4.458$ \\
$\mathrm{Mn}$ & $13.05 \pm 0.066$ & $7.10 \pm 0.104$ & $5.38 \pm 0.050$ & $21.53 \pm 1.667$ \\
$\mathrm{Se}$ & $3.13 \pm 0.040$ & $5.55 \pm 0.072$ & $3.06 \pm 0.029$ & $3.10 \pm 0.026$ \\
$\mathrm{Zn}$ & $52.88 \pm 0.536$ & $36.84 \pm 0.429$ & $35.31 \pm 0.457$ & $12.36 \pm 0.257$ \\
\hline
\end{tabular}

The heavy metal contents of 4 mushroom species were shown in Table 5 . The highest As level was $2.83 \mathrm{mg} / \mathrm{g}$ in $A$. bisporus and lowest in F. velutipes $(0.27 \mathrm{mg} / \mathrm{g})$. From the table, the highest Cd level was found as $2.11 \mathrm{mg} / \mathrm{g}$ for L. edodes, whereas the lowest Cd level was $0.08 \mathrm{mg} / \mathrm{g}$ in F. velutipes. The Cr level was comparatively high, ranging $1.94 \sim 2.66 \mathrm{mg} / \mathrm{g}$ for this four cultivated mushrooms in Zhejiang province. The heavy metal of As was determined in A. bisporus ( $2.83 \mathrm{mg} / \mathrm{g}$ ) and F. velutipes (0.16 mg/g). Interestingly, Hg was not detected in these four main cultivated mushrooms in Zhejiang province. The heavy metal of $\mathrm{Pb}$ was tested in F. velutipes and A. auricular, the higher level was 0.22 $\mathrm{mg} / \mathrm{g}$ for A. auricular and the lowest level was $0.09 \mathrm{mg} / \mathrm{g}$ for $F$. velutipes. It should be pointed that the maximum level for certain contaminants in foodstuffs established by the national standard is set at about 1.0, 1.5 and $0.2 \mathrm{mg} / \mathrm{kg}$ dry weight for $\mathrm{As}, \mathrm{Cr}$ and $\mathrm{Cd}$, respectively, in cultivated fungi. Therefore, As in A. bisporus, Cd in L. edodes and $\mathrm{Cr}$ in these four main cultivated mushrooms 
exceeded the national standard. Due to the growth compost, A. bisporus from Turkey was reported lower As but higher $\mathrm{Hg}, \mathrm{Pb}$, Cd than herein studied [9].

Table 5 Heavy metal level of four main cultivated mushrooms in Zhejiang province

\begin{tabular}{lllll}
\hline Heavy metal & L. edodes & A. bisporus & F. velutipes & A. auricula \\
\hline As & ND & $2.83 \pm 0.84$ & $0.16 \pm 0.28$ & ND \\
Cd & $2.11 \pm 0.42$ & $0.12 \pm 0.01$ & $0.08 \pm 0.04$ & $0.17 \pm 0.09$ \\
$\mathrm{Cr}$ & $1.94 \pm 0.18$ & $2.66 \pm 0.36$ & $2.34 \pm 0.19$ & $2.18 \pm 0.50$ \\
$\mathrm{Hg}$ & ND & ND & ND & ND \\
$\mathrm{Pb}$ & ND & ND & $0.09 \pm 0.04$ & $0.22 \pm 0.38$ \\
\hline
\end{tabular}

\section{Conclusion}

In this study, chemical composition and nutritional value of the main cultivated mushroom in Zhejiang province were compared. The results revealed that these four species contained high protein and low fat. They not only were rich in mineral elements, which were abundant in P, K, S, but also contained varieties of essential amino acids and non-essential amino acids. However, chemical composition and nutritional value in different species mushroom were varied. It should be pointed out that the levels of As in A. bisporus, Cd in L. edodes and $\mathrm{Cr}$ in these four main cultivated mushrooms exceeded the national standard. This study contributes to the elaboration of nutritional databases of the most consumed fungi species worldwide by comparison between them.

\section{References}

[1]. Reis FS, Barros L, Martins A, et al. Chemical composition and nutritional value of the most widely appreciated cultivated mushrooms: An inter-species comparative study. Food and Chemical Toxicology. Vol. 50 (2012) No. 2, p. 191-197.

[2]. Mattila P, Könkö K, Eurola M, et al. Contents of vitamins, mineral elements, and some phenolic compounds in cultivated mushrooms. Journal of Agricultural and Food Chemistry. Vol. 49 (2001) No. 5, p. 2343-2348.

[3]. Kalač P. Chemical composition and nutritional value of European species of wild growing mushrooms: a review. Food Chemistry. Vol. 113 (2009), No. 1, p. 9-16.

[4]. Yang JH, Lin HC, Mau JL. Non-volatile taste components of several commercial mushrooms. Food Chemistry. Vol. 72 (2001), No. 2, p. 465-471.

[5]. Manzi P, Gambelli L, Marconi S, et al. Nutrients in edible mushrooms: an inter-species comparative study. Food Chemistry. Vol. 65 (1999), No. 4, p. 477-482.

[6]. Lee KJ, Yun IJ, Kim KH, et al. Amino acid and fatty acid compositions of Agrocybe chaxingu, an edible mushroom. Journal fo Food Composition and Analysis. Vol. 24 (2011) No. 2, p. 175-178.

[7]. Mendez LA, Castro CAS, Casso RB, et al. 2004. Effect of substrate and harvest on the amino acid profile of Oyster mushroom (Pleurotus ostreatus). Journal of Food Composition and Analysis. Vol. 18 (2004), No. 5, p. 447-450.

[8]. Wang D, Sakoda A, Suzuki M. Biological efficiency and nutritional value of Pleurotus ostreatus cultivated on spent beer grain. Bioresource Technology. Vol. 78 (2001), No. 3, p. 293-300.

[9]. Sesli E, Tüzen M. Levels of trace elements in the fruiting bodies of macrofungi growing in the East Black Sea region of Turkey. Food Chemistry. Vol. 65 (1999), No. 4, p. 453-460. 